\title{
Oxide-metal core is possible transition to the metal fuel core for fast reactors of the BN-type
}

\author{
Yu. M. Golovchenko \\ Joint Stock Company “State Scientific Centre Research Institute of Atomic Reactors”, JSC "SSC RIAR”, Dimitrovgrad, 433510, Russia
}

Email address:

adm@niiar.ru

\section{To cite this article:}

Yu. M. Golovchenko. Oxide-Metal Core Is Possible Transition to the Metal Fuel Core for Fast Reactors of the BN-Type. International Journal of Energy and Power Engineering. Vol. 2, No. 3, 2013, pp. 113-120. doi: 10.11648/j.ijepe.20130203.15

\begin{abstract}
The article deals with the initial requirements for metal fuel elements and commercial reactors using this type of elements: high smear density of fuel, high technological effectiveness of fuel, fuel column and fuel elements; interchangeability of metal fuel elements and oxide fuel elements; achievement of fuel breeding ratio of the core $\mathrm{BRC} \sim 1.0$; prolongation of refuelling cycle up to Tc 11 months. The article presents content and results of examinations of radiation-thermal effects in U fuel column elements and UPu fuel column elements: irradiation of breeding and fuel elements in the BOR-60 and BN-350 reactors; research of macroeffects of radiation growth, radiation swelling, fuel-cladding chemical interaction. Applicability of the obtained results for developing advanced BN-reactors with heterogeneous cores of various types was discussed: with by FA heterogenization of the core (BFAH); intra FA heterogenization of the core (IFAH); intra fuel element heterogenization (IFEH).
\end{abstract}

Keywords: Fast Reactors, Heterogeneous Oxide-Metal Cores, Metal Fuel; Breeding and Fuel Elements, Irradiation in BOR-60 and BN-350, Postirradiation Examinations

\section{Introduction}

Large-scale, long-term operational and safe nuclear power engineering cannot be created without solving such important problems as:

- nuclear fuel breeding within closed nuclear fuel cycle (CNFC);

- disposal of the accumulated stocks of plutonium (of various grades - weapon and power-generating) for purpose of power generation;

- Transmutation and burning out of ecologically-hazardous wastes of CNFC, first of all minor-actinides ( $\mathrm{Np}, \mathrm{Am}, \mathrm{Cm})$.

These problems taken as a single complex can be solved best of all by using fast reactors with maximum hard neutron spectrum.

At present fast reactors with sodium coolant (reactors of the BN-type) are the most studied and can be considered the most accessible for solving problems like these. During irradiation of neutron-moderator-free fuel elements the neutron sprectrum can be maximum hard. Such fuel must be based on metal uranium.

An extensive, unique and favourable experience in application of metal uranium fuel in BN- reactors (EBR-II,
FFTF, etc) is gained in the USA. This experience also comprises many components of CNFC[1]. However, the experience is rather specific as it is based on application of special fuel (alloy of uranium with $10 \% \mathrm{wtZr}$ ), fuel elements of the special design (sodium filling, upper gas plenum), peculiar techniques of fuel column fabrication (injection casting in quartz tubes) and spent fuel reprocessing (pyroelectrochemical procedure).

Previous experience and its features were analyzed in the $60 \mathrm{~s}-70 \mathrm{~s}$ and a conclusion was made that it is necessary to develop own concept of metal fuel application in BN-reactors.

\section{Initial Requirements for Metal Fuel Elements}

Initial requirements for metal fuel elements were formulated many years ago. They are listed and discussed below: 


\subsection{The Elements under Development Must Meet the Principle of Interchangeability with Standard Oxide Fuel Elements (With Helium Filling and Lower Gas Plenum) Designed For Application in the Exisitng (BOR-60, BN-350, BN-600) and Being Developed (BN-800, BN-1600, Etc) Reactors.}

This requirement is determined by necessity of large-scale life tests of full-size mockup fuel elements under the modes planned for advanced commercial fast reactors of the BN-type. Russian BN-reactors are aimed at applying ceramic (oxide, nitride) fuel elements with helium filling in which gas plenum for accumulation of gas fission products is located in the bottom low-temperature part to increase the effective capacitance.

On the contrary, gas plenum for accumulation of gas fission products in $\mathrm{U}-\mathrm{Zr}$ fuel elements filled with sodium must be located in the upper high-temperature part. This excludes the possibility that representative tests of full-size metal fuel elements filled with sodium will be performed in the $\mathrm{BN}$-cores consisted of ceramic fuel elements filled with helium. This circumstance had an influece upon decision of Indian specialists to design and construct the testing reactor MFTR of 320MW in thermal power for testing full-size metal fuel elements as a part of full-size FAs which are typical of commercial power-generating $\mathrm{BN}$ - reactors to be constructed [2].

There are different features typical of U-Zr fuel elements with sodium filling. Instability in fuel column dimensions is among them. Instability becomes apparent firstly in free elongation of fuel column inside the cladding, which is bad for the geometry and thermal-physical characteristics of the core [3]. This disadvantage is aggravated with so-called "lift-effect" - upward movement of the fuel column inside the cladding (toward the upper part). The effect was first found in EBR-II fuel elements. The explicit "lift-effect" was observed in $\mathrm{U}-18 \% \mathrm{Pu}-10 \% \mathrm{Zr}$ fuel elements filled with sodium and irradiated in BOR-60 up to the peak burnup of $9,6 \%$ h.a. Fuel columns of $450 \mathrm{~mm}$ in length moved over $15 \ldots 143 \mathrm{~mm}$. The cause of upward movement of heavy fuel column inside the cladding with light sodium filling was supposed to be reactor upright fuel column vibration resulting in gas bubble formation [4]. No effective ways of eliminating this undesirable effect have been described in known references.

Thus, only metal fuel elements with He-filling and low gas plenum can comply with a principle of interchangeability.

\subsection{Smear Density Of Heavy Atoms In The Elements Under Development Should Be Larger Than The One In Known Elements Of The Similar Purpose With Oxide, Carbide, Nitride Or Metal Fuels.}

Table 1 presents averaged values of nuclear fuel types, fuel elements and reactors using these fuel types. The data are well-known, very important for practical purposes and taken from different references.

Analysis of physical, thermal-physical and radiation-thermal properties of ceramic and metallic fuels presented in table 1 is necessary but insufficient for selection of the best fuel for the commercial reactor of the fourth generation. At the same time it follows from the table that so-called "dense" fuels (UPuN, UPuC, UPu-10Zr) are "twins" in the most important parameter - density of heavy atoms in fuel elements $\left(\gamma_{\text {eff: }} \approx 11 \mathrm{~g}\right.$ h.a. $\left./ \mathrm{cm}^{3}\right)$. In this parameter they are greatly superior to oxide low-dense fuel, but evidently inferior to high-dense alloy-free metallic fuel.

Nevertheless, by different reasons $\mathrm{U}-10 \mathrm{Zr}$ and $\mathrm{UPu}-$ $10 \mathrm{Zr}$ fuels developed and investigated in Argonne National Laboratory (USA) are obviously preferred out of all high-alloy metallic fuels in many countries (Japan, Korea). At the same time metal fuel (dense UPu-Zr or high-dense $\mathrm{UPu}$ ) in India will be selected from results of comparative reactor tests of fuel elements either with $\mathrm{Na}$ - or He-filling [5].

Advantages and disadvantages of metal fuels and appropriate fuel elements under test are not limited by fundamentally important differences in theoretical density $(15,7$ $\mathrm{g} / \mathrm{cm}^{3}$ and $19 \mathrm{~g} / \mathrm{cm}^{3}$ ) and smear density of heavy atoms in the fuel elements ( $\leq 11 \mathrm{~g}$ h.a. $/ \mathrm{cm}^{3}$ and $\geq 13 \mathrm{~g}$ h.a. $/ \mathrm{cm}^{3}$ ). Together with known advantages of U-10Zr- and UPu-10Zr fuel elements with Na-filling a number of their peculiarities should be noted determining specific parameters of fuel cycle on the whole:

- difficulty of initial homogenization of fuel and monitoring of homogenization;

- Decrease in heat conductance of fuel (by $\approx 20 \%$ );

- increase in Pu content in fuel;

- $\mathrm{Zr}$ radial redistribution in fuel column during irradiation ;

- difficulties of filling of "fuel column- cladding" gap and monitoring of filling quality ( 9 specific operations [6]);

- increase in initial length of fuel element (development of high-temperature gas plenum and sodium collector);

- unacceptability of aqueous reprocessing of Na-containing spent fuel elements;

- hazard of storage and ultimate storage of Na-containing spent fuel elements.

Table 1. Most important characteristics of fuel types. [1,5]

\begin{tabular}{llllll}
\hline Fuel type & Oxide & Dense & & \multicolumn{2}{c}{ High-dense } \\
Characteristics & UO2, & UN, & UPuC & U-10Zr, & U,(UPu) \\
Theoretical density, $\mathbf{g} / \mathrm{cm}^{3}$ & UPuO2 & UPuN & $10 Z$ r) & 19 \\
\hline
\end{tabular}




\begin{tabular}{|c|c|c|c|c|c|}
\hline Density of heavy atoms, $\mathrm{g}$ h.a. $/ \mathrm{cm}^{3}$ & 9,7 & 13,4 & 13,0 & 14,2 & 19 \\
\hline Smear density of heavy atoms in a fuel element, $\mathrm{g}$ h.a. $/ \mathrm{cm}^{3}$ & 8 & $\leq 11$ & $\leq 11$ & $\leq 11$ & $\geq 13$ \\
\hline Ratio of atoms-moderators, at. \% & 67 & 50 & 50 & 0 & 0 \\
\hline Melting temperature, ${ }^{\circ} \mathrm{C}$ & 2800 & 2850 & 2350 & $1190(1127)$ & $1130(1000)$ \\
\hline Heat conductivity, $\mathrm{W} / \mathrm{m}{ }^{\circ} \mathrm{K}$ & 2,6 & 15,8 & 18,8 & 25 & 33 \\
\hline $1000 \mathrm{~K}$ & 2,4 & 20,1 & 21,2 & & \\
\hline $\begin{array}{l}2000 \mathrm{~K} \\
\text { Radiation swelling coefficient } \\
\mathrm{S}=\Delta \mathrm{V} / \mathrm{V}, \% / \mathrm{B}, \%\end{array}$ & 0,3 & 1 & 1 & 8 & $>10$ \\
\hline Breeding ratio of the core & $<1,0$ & $\approx 1,0$ & $\approx 1,0$ & $\approx 1,0$ & $>1,0$ \\
\hline Total breeding ratio & 1,15 & 1,25 & 1,25 & 1,4 & $>1,5$ \\
\hline
\end{tabular}

These unfavorable features of high-alloy metallic fuel and fuel elements with sodium filling were incentive for RIAR specialists to do research and developments of low-alloy metallic fuel and fuel elements with He filling.

The objective of the investigations and developments was to seek ways of reducing to the minimum expected unfavorable consequences of application of such fuel and fuel elements and to estimate their effectiveness. The consequences could be caused by such special radiation-thermal properties of high-dense low-alloy (including alloy-free) metal fuel as:

- intense radiation growth of uranium and alpha-phase uranium alloys;

- intense radiation swelling of uranium and uranium alloys;

- increased FCCI (fuel-clading chemical interaction between steel claddings and low-alloy uranium, U-Pu alloys in particular);

- presense of low-temperature phase transformation and decreased melting temperature of low-alloy uranium and U-Pu alloys in particular.

During development and estimation it was necessary to orient to techological effectiveness of techniques, including remotely-controlled conditions.

\subsection{Production Methods Of Fuel, Fuel Columns, Fuel Elements And Fas Should Be Aimed At Maximum Use Of Available Equipment, Processes Techniques And Experi- ence.}

The initial requirements determined necessity of maximum use of available equpment, techniques and experience in manufacturing oxide fuel elements with He-filling for $\mathrm{BN}$-reactors and metal $\mathrm{U}$ fuel elements for previous commercial uranium -graphite reactors (CUGR). The same requirements determined necessity of simplifying the known procedures as applied to remotely-controlled conditions.

Thus, the developed and commercialized "metallurgy procedure" of microalloying and thermal-mechanical processing of metal uranium was found to be unacceptable. The procedure was used to form monitored fine-grained texture-free fuel column, which excluded deformation of fuel column and cladding resulting from macroeffects of uranium radiation growth.

That is why, "design approaches" were studied based on mechanical restraints of macroeffects of radiation growth of alpha-uranium monocrystals, polycrystal specimens and full-size fuel columns within the preset limits. Alpha-uranium fuel columns of various compositions were studied, including: alloy-free (of technical purity), non-heat-treated, coarse-grained and textured ones produced in accordance with various simplified procedures acceptable for remotely-controlled conditions. Fig.1 presents shapes of produced full-size fuel columns used for reactor tests.

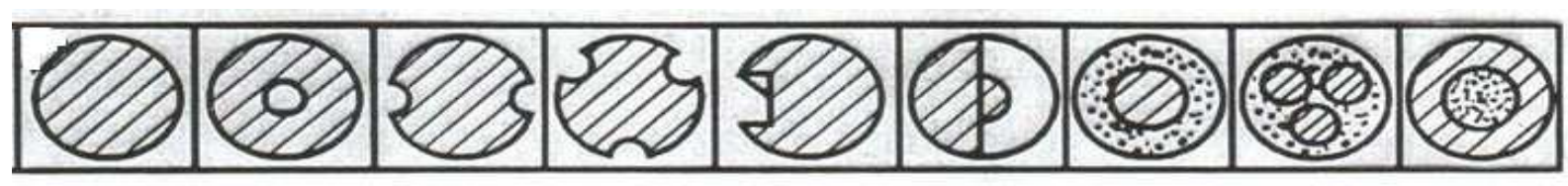

Fig 1. Shape of metal fuel columns in the studied elements

Steel claddings of standard dimension types $(\mathrm{d} \times \delta=$ $5,5 \ldots 14,5 \times 0,3 \ldots 0,5 \mathrm{~mm}$ with "design strength" of $\delta / d=0,3 \ldots 0,11)$ provided mechanical restraints of macroeffects of radiation growth of full-size fuel columns. It was established that mechanical restraint of uranium radiation growth was feasible and complete or partial restraint of steel claddings deformation was possible depend- ing on composition, shape and texture of the fuel column, "design strength" of the cladding and irradiation temperature. Fig. 2 presents one of the versions of uranium fuel column-steel cladding deformation - a plastic fuel column strain and ovalization of low-strength $(\delta / \mathrm{d}=0,03)$ steel cladding.

It followed from the results of the special experiments 
that revealed mechanical restraint of radition growth of alpha uranium and uranium alloys could be explained. The experiments consisted in complete and partial mechanical restraint of radiation growth of uranium monocrystals (various crystallographic orientations) and polycrystalline textured specimens done in accordance with the schemes presented in fig.3.
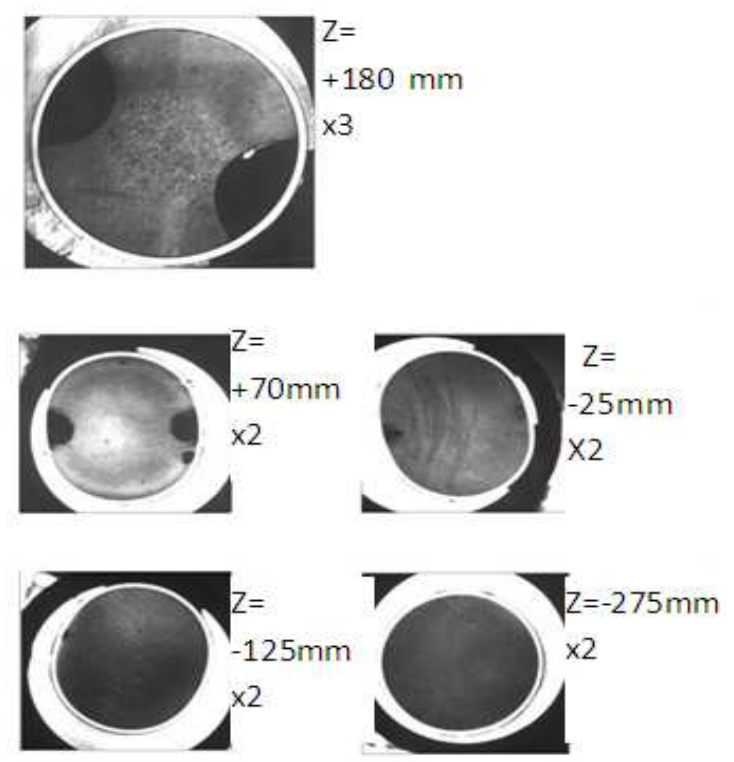

Fig 2. U fuel-steel cladding ( $d x \delta=14,5 x 0,45 \mathrm{~mm})$ deformation in different sections along the fuel element length of FA U-805 irradiated up to $2 \%$ h.a. for 8.5 years in the BOR- 60 radial blanket

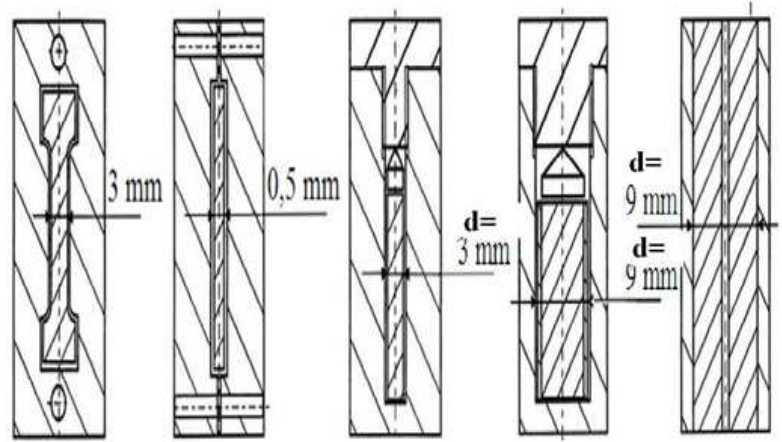

Fig 3. Schemes of devices for mechanical restraint of uranium specimens radition growth.

It was established from postirradiation examinations [7]:

- Irradiated polycrystalline metal uranium had residual plasticity when compressed. It is explained by the fact that critical shearing stress of twinning along rational crystallographic planes (130) achieves saturation on a low enough level both under free and mechanically restrained radiation growth $\left(\sigma_{\mathrm{s}}=25 \mathrm{MPa}\right.$ at $\mathrm{T}_{\text {test }}=20^{\circ} \mathrm{C}$ after $\mathrm{B} \geq 0,02 \%$ h.a.);

- Mechanical stresses, restraining radiation growth of monocrystal and textured polycrystalline uranium called by "uranium radiation growth stress $\sigma_{\mathrm{g}} »$, are proportional to the degree of initial uranium strengthening. They are minimum for uranium monocristals $\left(\sigma_{\mathrm{g}}=65 \ldots 72 \mathrm{MPa}\right.$ at $\left.100^{\circ} \mathrm{C}\right)$ and maximum for high-strength alpha-phase composition materials of $\mathrm{U}-\mathrm{BeO}, \mathrm{U}-\mathrm{ZrC}$ types $\left(\sigma_{\mathrm{g}}>230 \mathrm{MPa}\right.$ at $\left.450550^{\circ} \mathrm{C}\right)$.

Integrated investigations of macroeffects of uranium radiation growth substantiated applicability of commercial materials, developed technologies and previous experience for manufacturing alloy-free (technical purity) metal uranium fuel elements for axial and radial blankets of the $\mathrm{BN}$-reactors intended for oxide fuel use in the core.

Besides, it was known that BN-reactors with oxide fuel core were characterized by decreased parameters of inherent safety as a result of insufficiently high content of heavy atoms in fuel, fuel elements and the core. To eliminate the disadvantage various versions of so-called "heterogeneous" cores were proposed and validated. Heterogeneous cores are characterized by introducing additional U-238 masses in the form of breeding elements or breeding assemblies into the core. Filling of breeding elements was considered either with uranium dioxide [8] or high-dense uranium metal studied at RIAR [9].

Unlike the outer breeding zone having moderate temperatures and burnups, these parameters in the fuel elements of the inner breeding zones are high enough and may be dangerous from the viewpoint of efficiency retaining. The planned hazards are due to high rates of high-temperature radiation swelling of low-alloy and so much the more alloy-free metal fuel column, volume changes in the fuel columns resulting from phase transformations which increase inevitably fuel-cladding mechanical interaction (FCMI).

Different methods were studied to limit volume changes of metal fuel columns caused by radiation swelling. More than 200 uranium alloys irradiated in sodium-filled ampoules (free swelling conditions) under various modes were used to study effectiveness of conventional "metallurgical procedures" based on alloying and thermal treatment. Fig. 4 presents results of a series of such experiments.

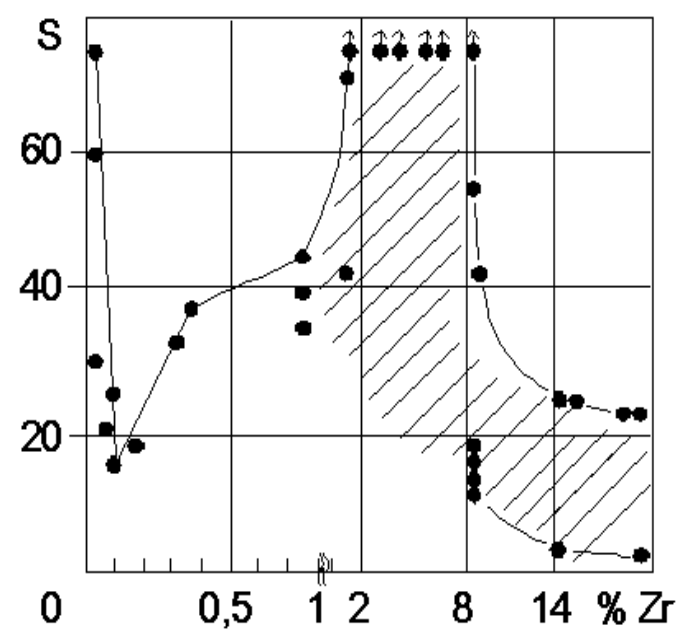

Fig 4. Dependence of swelling of uranium alloys on zirconium content. 
It should be noted, that firstly increase in alloying additive (herein $-\mathrm{Zr}$ ) content can result either in decrease or increase in radiation swelling rate (coefficient) S. Secondly, only inadmissibly high content of alloying additive can provide acceptably small values $\mathrm{S}$.

Effectiveness of "design approaches" was studied. They were based on mechanical restraints of volume changes of fuel columns consisted of metal uranium or alloys based on uranium placed into steel claddings. It followed from the results of these experiments that within the preset limits it is possible to restrain mechanically volume changes at temperatures $\mathrm{T}_{\mathrm{f}}>650^{\circ} \mathrm{C}$ characteristic of fuel columns in fuel elements with helium filling. FCMI are greatly influenced by smear density of fuel, "design strength" of the cladding and burnup. But the degree of alloying can be left out of the parameter of importance for FCMI. This conclusion was drawn from measured differences in mechanical properities of the irradiated fuel element components: steel cladding, high-alloy and alloy-free fuel columns fragments (fig.5).

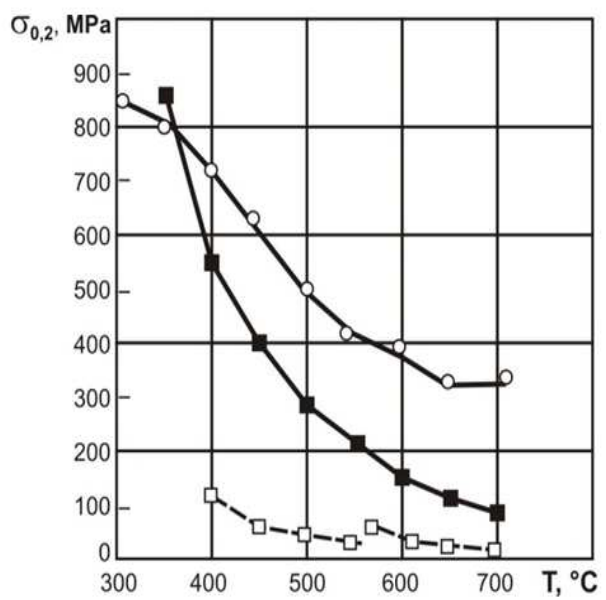

Fig 5. Dependence of yield strength of irradiated fuel and cladding materials on test temperature

$0-$ tensile tests of ring specimens (steel EI-847), $\mathrm{F}=61 \mathrm{dpa}, \mathrm{T}_{\text {test. }} \approx \mathrm{T}_{\text {irr. }}$. compression of cylindrical specimens U-13 Pu-11 Zr, Mo, Nb; B=6.3\% h.a. $\square-$ compression of cylindrical specimens $U-15 \mathrm{Pu}, \quad \mathrm{B}=6.3 \%$ h.a.

The conclusion was confirmed from experiments of another type - during postirradiation measurements of the forces applied by fuel column fragments under heating. So-called "swelling stresses" $\sigma_{\mathrm{s}}$ were calculated. They proved to equal $\sigma_{\mathrm{s}}=\mathrm{S}=5 \pm 1 \mathrm{MPa}$ for the most and the least gas swelling-resistant fuels (U-0,5 $\mathrm{BeO}$ and $\mathrm{U}$ ).

Real hazards are due to fuel-cladding chemical interaction (FCCI) metal fuel-steel cladding interaction. The hazards increase as plutonium in uranium fuel columns accumulates resulting in cladding temperature rises.

The decision was taken to reduce the hazards to the minimum by "design approaches". The approaches are based on principle of mechanical separation of the metal fuel column from the steel cladding by means of antidiffusion layers.
Various methods of applying protective layers on the outer surface of metal fuel columns (oxide, oxicarbide and other layers), on the inner surface of steel claddings (Cr, W and others) were studied.

Effectiveness of the layers were evaluated in the course of prior-to-irradiation, irradiation and postirradiation examinations. Fig. 6,7 presents some results of the examinations.

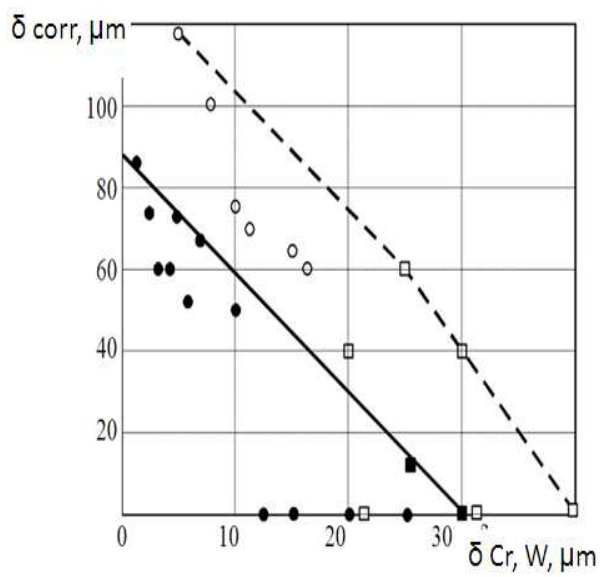

Fig 6. Depth of corrosion damage of EI-847 claddings with protective layers $\mathrm{Cr}(\mathrm{O})$ or $\mathrm{W}(\square)$ of different thickness; $\boldsymbol{\square}$-the same, when fuel oxygenized

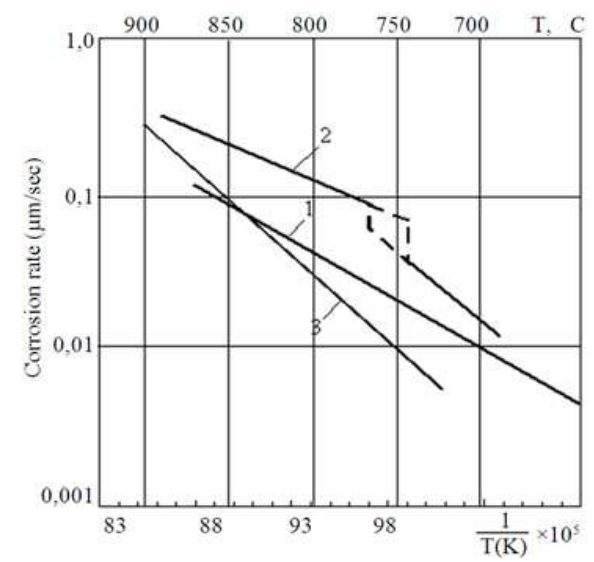

Fig 7. Cladding corrosion rates as a function of postirradiation overheating temperature. 1-ANL (U,Pu-10 Zr); 2-RIAR (U, Pu); 3-RIAR (UPu + protective layers)

The obtained results indicate that application of antidiffusion protective layers of $5 . . .40 \mu \mathrm{m}$ in thickness on contacting surfaces "steel cladding- alloy-free metal fuel" is the most effective, if oxide and metal layers combine (fig.6). Under emergency postirradiation overheatings upto $\mathrm{T} \leq 825{ }^{\circ} \mathrm{C}$ this combination of protective layers is no less effective than introduction of $10 \% \mathrm{Zr}$ in fuel composition (fig.7).

One of the advantages of zirconium-alloyed metal fuel is considered "a larger margin to the melting temperature of fuel column". But the advantage disappears when comparing between the core of the standard layout with fuel elements containing high-alloy U-19Pu-10Zr fuel columns 
$\left(\mathrm{T}_{\mathrm{mlt}}=1127^{\circ} \mathrm{C}\right)$ and heterogeneous oxide-metal core with breeding elements containing alloy-free uranium column $\left(\mathrm{T}_{\mathrm{mlt}}=1130^{\circ} \mathrm{C}\right)$.

Besides, the advantage is declared of fuel elements with high heat-conducting Na-filling, which is necessary for high-alloy uranium fuel columns having low rates of radiation swelling. This advantage over helium-filling fuel elements remains unchangeable during initial irradiation stages and becomes insignificant after formation of close fuel-cladding contact in the form of alloy-free uranium having high rates of radiation swelling.

It follows from the results that values of the contact heat conductivity in these elements achieve values $\alpha_{\mathrm{K}} \geq 4$ $\mathrm{W} / \mathrm{cm}^{2} \cdot{ }^{\circ} \mathrm{C}$. Taking into account the maximum high heat conductivity of alloy-free uranium, these fact determines possibility of operation of such elements without being concerned about melting of uranium fuel column under linear power loadings taken for $\mathrm{BN}$ oxide fuel elements $\left[q_{l}^{\max }\right] \leq 500 \mathrm{~W} / \mathrm{cm}$.

\subsection{Methods of Spent Fuel Reprocessing Must Allow Aqueous Methods to Be Used}

This initial requirement is met when using the commercialized aqueous processes of the PUREX type, which provide non-isolation of plutonium from spent fuel reprocessing products. At the same time nothing keeps researchers from using known piroelectrochemical reprocessings in the molten salts.

Thus, it follows from analysis of research and developments results, that initial requirements for metal fuel elements intended for application in heterogeneous oxide-metal core of advanced BN-reactors can be met.

\section{Initial Requirements for Metal Fuel Cores}

Previously stated initial requirements for metal fuel elements remain valid nowadays, when a concept of large-scale commercial BN-reactors of a new generation is being formed. In addition, the requirements of limit safety, maximum cost-effectiveness and versatility of the $\mathrm{BN}$-reactors have been made.

3.1 BN-reactors with inherent safety meet the requirement of the limiting safety. The most important condition of inherent safety is a value of the breeding ratio of the core about 1.0. BRC at least 1.0 can be achieved either in ordinary metal fuel core or in heterogenuous oxide-metal fuel core $[10,11]$.

3.2. Components of the maximum cost-effectiveness requirement are numerous and various. Among the most important components there are duration of inter-refuelling cycle (microcycle) ( $\mathrm{T}_{\mathrm{c}} \sim 11 \mathrm{months}$ is desirable); fuel burnup factor (it is desirable to have $\mathrm{B}^{\mathrm{max}}=15 \ldots 20 \%$ h.a. for oxide fuel with appropriate damage dose for fuel element cladding); peak (acceptable and safe) temperature of fuel ele- ment claddings $\left(\mathrm{T}_{\text {clad }}{ }^{\max }=700^{\circ} \mathrm{C}\right.$ is desirable, $\quad \mathrm{T}_{\text {clad }}{ }^{\max }$ $=650^{\circ} \mathrm{C}$ is acceptable for heterogeneous core); use of commercialized fuel types, use of commercialized cladding steels that confirmed radiation resistance under set temperature-dose modes.

Assessment of cost-effectiveness is unlikely to be persuasive for a large-scale commercial BN-reactor with the core of standard layout loaded with fuel elements consisting of noncommercialized fuel columns (plutonium -containing carbide, nitride, metal) and noncommercialized claddings (of ODS type), which are operated in the insufficiently studied ranges of temperature-dose.

At the same time there is a bank of concrete results of reactor tests and postirradiation examinations of experimental fuel and breeding elements that meet all the stated above requirements of cost-effectiveness of the reactor with heterogeneous oxide-metal core.

3.3. Requirements of commercial $\mathrm{BN}$-reactors versatility can be apparently related only to prototype models of the reactors. The following tasks can be stated for such versatile reactor:

- varied nuclear fuel breeding;

- burning out of the accumulated ecologically-hazardous wastes of CNFC (fission isotopes);

- transmutation of long-living ecologically-hazardous wastes of CNFC (non fission isotopes);

- production of isotopes of technical and medical purposes.

The BN-reactor with heterogeneous oxide-metal core (with varied BRC) is the most suitable to solve these tasks.

\section{Peculiarities of Heterogeneous Oxide-Metal Cores and Appropriate Elements}

Significant features of these cores and elements are the following $[10,11]$ :

- ratio of MOX-fuel volume to breeding metal (U-238) volume equal to $2: 1$ makes it possible to achieve BRC $\sim 1.0$

- rate of reactivity drop with a fuel burnup change decreases and microcycle increases up to 11 months;

- MOX-fuel with high plutonium content is used, no variations in dimensions of fuel element claddings and element-to-element pitch in FA are observed;

- MOX-fuel burnup factor increases by $\sim 25 \%$ at preset (admissible, safe) damage dose for cladding and duct steels;

- MOX-fuel output and production quantity of MOX FAs decreased by $\sim 30 \%$ and down to $\sim 30 \%$ appropriately with correponding reduction of the costs for these remotely-controlled productions.

Oxide-metal heterogeneous core (OMHC) is characterized by possibility of realization in various forms (fig.8): by FA heterogenization of the core $(\mathrm{BFAH})$; by intra FA 
heterogenization of the core (IFAH); by intra fuel element heterogenization (IFEH).

In metal uranium fuel elements such parameters as plutonium accumulation, linear power loadings, temperatures of fuel column and cladding increase monotonously and achieve peak values by the end of fuel element operation for any version of a heterogeneous core. According to the calculations, values of the "end" parameters are close to the "start" parameters of U-Pu metal fuel elements in standard cores.

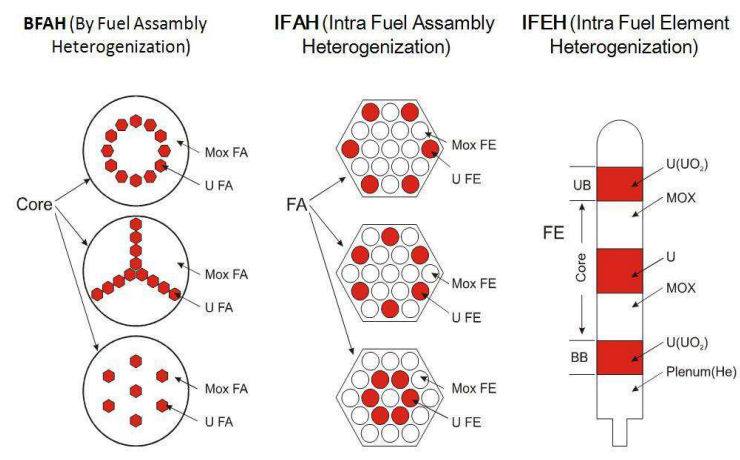

Figure 8. Oxide-metal heterogeneous cores with U: MOX 30\%

\section{Main Results of Development and Research of Elements for Oxide-Metal Heterogeneous Cores}

\subsection{Breeding and Fuel Elements with Metal Fuel Columns}

Radiation-thermal characteristics of uranium-containing metal fuel which have influence on reliability of breeding and fuel elements of the BN-reactors have been studied. Particularly, macroeffects of radiation growth of metal fuel columns in steel claddings, macroeffects of radiation swelling of uranium and uranium-containing alloys in free state and in steel claddings; macroeffects of physical-chemical interaction of uranium and U-Pu alloys with steel claddings were investigated [12].

The following dependences of the macroeffects were established: on type and mass content of additives (0,3 40 $\mathrm{wt} \% \mathrm{Me}, \mathrm{MeO})$, on irradiation temperature $\left(\mathrm{T}_{\mathrm{f}}=100 \ldots 900^{\circ} \mathrm{C}\right)$, on burnup factor $(\mathrm{B} \leq 10,4 \%$ h.a. $)$, on burnup rate $\left(1 \times 10^{13}\right.$ fiss $\left./ \mathrm{cm}^{3} \mathrm{sec} \leq \omega \leq 12 \times 10^{13} \mathrm{fiss} / \mathrm{cm}^{3} \mathrm{sec}\right)$, on "design strength" of steel claddings $(\delta / d=0,030,11)$, on cladding temperature under irradiation $\left(\mathrm{T}_{\text {clad }}{ }^{\max } \leq 750^{\circ} \mathrm{C}\right)$ and postirradiation emergency overheating $\left(\mathrm{T}_{\mathrm{f}}^{\max }=\mathrm{T}_{\text {clad }}{ }^{\max } \leq 900^{\circ} \mathrm{C}\right)$, on smear density of fuel in mockup elements and full-size elements $\quad\left(\gamma_{\text {eff }}=12 \ldots 18 \mathrm{~g} \mathrm{h.a.} / \mathrm{cm}^{3}\right)$, on type and thickness of antidiffusive protective layer in the boundary "metal fuel column - steel cladding" (nonmetal and metal layers of $5 \ldots 40 \mu \mathrm{m}$ in thickness).

The established dependences were used for developing and manufacturing experimental metal uranium elements oriented to the operating conditions in oxide-metal cores of various types: BFAH, IFAH, IFEH.

Main features of the elements are the following:

- claddings - austenitic steel EI-847 of standard type-dimensions: $\mathrm{d} \times \delta=6.0 \times 0.3 \mathrm{~mm}$; $6.9 \times 0.4(0.5) \mathrm{mm} ; 14.5 \times 0.45 \mathrm{~mm}$;

- filling of the elements - helium;

- fuel columns - alloy-free uranium (depleted, natural, enriched, with additives of up to $8 \% \mathrm{wt} \mathrm{Pu}$ );

- smear density of fuel - $12 \ldots 18 \mathrm{~g} \mathrm{h.a.} / \mathrm{cm}^{3}$;

- design similarity to the standard oxide fuel elements applied in the BOR-60, BN-350, BN-600 etc reactors.

The elements were tested in various zones of the BOR-60 and BN-350 reactors (the core, radial blanket, axial blankets) incorporated in experimental FAs that are similar to standard FAs in geometric and operating parameters. Thus, the initial requirement of interchangeability of standard and experimental FAs was realized in operational and being designed BN-reactors. In all about 50 full-size FAs of various types and purposes were tested in standard operating modes of the BOR- 60 and BN-350 reactors. Duration of standard and experimental fuel elements irradiation is restrained by the maximum admissible fluence of fast neutrons on EI-847 cladding $\left(1.1 \times 10^{23} \mathrm{n} / \mathrm{cm}^{2} \Rightarrow 55 \mathrm{dpa}\right)$.

It follows from postirradiation examinations that specific macroeffects of radiation growth and radiation swelling of alloy-free metal fuel and also metal fuel-steel cladding physical-chemical interaction do not interfere with this fuel application in the BN heterogeneous cores of BFAH, IFAH, IFEH types.

The obtained results were used for substantiating possibilities of stepwise replacement (according to the chosen plan) of standard oxide fuel elements by similar metal uranium fuel elements with high smear density $\left(\gamma_{\text {eff }}=13 \mathrm{~g}\right.$ h.a. $/ \mathrm{cm}^{3}$ ) for transition to oxide-metal heterogeneous core of the chosen type (BFAH, IFAH, IFEH).

Elements with $\mathrm{U}-8 \% \mathrm{Pu}$ fuel columns (simulators of the limit $\mathrm{Pu}$ accumulation in breeding elements) and $\mathrm{U}-15 \% \mathrm{Pu}$ fuel columns (experimental fuel elements) were designed, manufactured and tested in the BOR-60 reactor. Postirradiation examinations showed that radiation-thermal macroeffects of these elements were similar to those in breeding elements with uranium fuel columns.

In the course of calculations no significant differences were found in power generation and reliability of $\mathrm{UPuO}_{2}$ fuel elements $\left(\gamma_{\text {eff }}=9 \mathrm{~g} / \mathrm{cm}^{3} \Rightarrow 8 \mathrm{~g}\right.$ h.a. $\left./ \mathrm{cm}^{3}\right)$, U-Pu-10 $\mathrm{Zr}$ fuel elements $\left(\gamma_{\text {eff }}=11,8 \mathrm{~g} / \mathrm{cm} 3 \Rightarrow 10,7 \mathrm{~g} \mathrm{h.a.} / \mathrm{cm}^{3}\right)$ and alloy-free U-Pu fuel elements $\left(\gamma_{\text {eff }}=13 \mathrm{~g}\right.$ h.a. $\left./ \mathrm{cm}^{3}\right)$ which are similar in geometric and operating parameters

\subsection{Oxide Fuel Elements}

High burnup of MOX fuel ( $\mathrm{B}^{\max }=15 \ldots 20 \%$ h.a.) in the commercial fast reactor $\mathrm{BN}-\mathrm{C}$ can be achieved when using claddings made of low-swelling ferritic-martensitic steels of the EP-450 type.

Reactor capabilities of the fuel elements with such clad- 
dings and oxide fuels (including vibropac MOX-fuel) were studied during irradiation in the BOR-60 reactor and postirradiation examinations. In these experiments claddings of the standard type-dimension made of commercialized steel EP-450 were used.

In the course of the experiments irradiation parameters achieved and even exceeded the operating parameters planned for the $\mathrm{BN}-\mathrm{C}$ reactor. For example, the following parameters were achieved $\mathrm{q}_{1} \sim 475 \mathrm{~W} / \mathrm{cm} ; \mathrm{T}_{\text {clad. }}{ }^{\max } \sim 700^{\circ} \mathrm{C}$; $\mathrm{B}^{\max }$ more than $20 \%$ h.a . [13]

\section{Conclusions}

During development of a commercial fast reactor of the $\mathrm{BN}-\mathrm{C}$ type of a new generation it is possible to orient oneself to RIAR's experience in the fields of development and research of experimental metal uranium elements and experimental vibropac MOX fuel elements.

This experience indicates that main problems of $\mathrm{BN}-\mathrm{C}$ can be solved for heterogeneous oxide-metal core of BFAH, IFAH or IFEH types containing elements which are manufactured by using commercialized methods and materials.

Interchangeability of standard oxide fuel elements and developed metal uranium elements defines possibility of planned conversion of the standard oxide core into heterogeneous oxide-metal and, if necessary, into the standard metal fuel core.

Possibilities of construction of commercial LMFR-1000 with standart metal fuel core are under consideration in India. It is obvious that RIAR's experience in R\&D of metal fuel elements was used, namely application of fuel columns with lateral grooves outside, fabrication of U-Pu fuel column without additional $\mathrm{Zr}$ alloying, fuel element filling with helium [5].

Possible cooperation of RIAR with American firm TerraPower is under consideration. Terra power develops advanced fast reactors of new purposes on the basis of "travelling wave" TWR [14]. In the course of cooperation RIAR's experience can be used in fuel elements and breeding elements containing metal uranium alloy-free fuel columns for development of heterogeneous metal-metal cores of various types.

\section{References}

[1] Status and Trends of Nuclear Fuels Technology for Sodium Cooled Fast Reactors. IAEA Nuclear Energy Series №
NF-T-4.1, Vienna.2011

[2] K. Devan, Debanwita Paul, Abhitab Bachchan et al. Physics Design and Safety Studies of a 320 MWt Experimental Metal FBR// International Conference FR 13, Paris, 4-7 March 2013, T 01 Paper 299.

[3] E.R. Cramer, A.L. Pitner. In situ observation of axial irradiation growth in liquid-metal reactor metal fuel//Trans. Amer. Nucl. Soc. 1989, 60, 306-307.

[4] S.V. Pavlov, A.V. Sukhikh, S.S.Sagalov. Gamma-spectrometry in reactor material-science. Dimitrovgrad: JSC “SSC RIAR”, 2012, 314p.

[5] Arun Kumar. Development, fabrication and characterization of fuels for Indian fast reactor programme //International Conference FR 13, Paris, 4-7 March 2013,T 05, Paper № 025 .

[6] G. Ravisankar. Metal alloy and Sphere-Pac MOX test fuel fabrication for irradiation in FBTR.// International Conference FR 13, Paris, 4-7 March 2013, T 05 Paper 213.

[7] Y.M. Golovchenko. Scientific validation of absorbing, breeding and fuel elements with metal uranium columns for fast reactors of the BN type. Dissertation, M., 2002.

[8] Su S.F., Orechwa Y., Barthold W.P. Configuration optimization of high-performance 1000-MWe oxide heterogeneous cores. - Annual Meeting of American Nuclear Society, Las Vegas. Nev., 1980. Summaries. - «Trans. Amer. Nucl. Soc.», 1980, 34, 780-781.

[9] O.D. Kazachkovsky, V.A. Tsykanov, V.B. Lyitkin, I.S. Slesarev. Fast breeder reactors in nuclear power development - «ENS - 3 Proc.: Int. Conf. New. Dir. Nucl. Energy Emphasis Fuel Cycles, Brussels, 26-30 Apr., 1982. Proc. Plenary Sess.» Brussels, 1982, 495-502.

[10] M.F.Troyanov, A.A.Rineisky, A.A.Kamaev. Possible ways of achieving limit characteristics of fast reactors safety. Atomnaya energiya,V.66, No.4, April 1986, 235-238.

[11] P.N.Alexeev, Yu.A.Zverev, A.G.Morozov, V.V.Orlov et al. Concept of new generation reactor of high-level safety with liquid-metal coolant LMFR. Atomnaya energiya, V.66, No.3, March 1989, 155-158

[12] Y.M. Golovchenko. Experience of Developments and Tests, Application of High-Dence Metallic Fuel in Fast Reactors // Proceedings of GLOBAL 2011, Makuhan,Japan, Dec. 11-16, 2011. Paper № 392457.

[13] A.A.Mayorshin. Vibropac oxide fuel pins- Dimitrovgrad: FSUE “SSC RF RIAR” 2007. - 327 p.

[14] American company TerraPower can become a new partner of RIAR.//http://www. atomic-energy.ru/news/2010/09/06/13604. 